\title{
Dimensionamento da oferta de produtos perecíveis a uma rede varejista por meio de métodos de previsão
}

Antonio do Nascimento Branco antoniobrancov33@gmail.com

niversidade Federal de Santa Maria (UFSM), Santa Maria, Rio Grande do Sul, Brasil

Fernanda dos Santos Silva nandasantos.eng@gmail.com Universidade do Estado do Pará (UEPA) Castanhal, Pará, Brasi

Denilson Ricardo de Lucena Nunes

denilson.lucena@gmail.com

Universidade do Estado do Pará (UEPA), Castanhal, Pará, Brasil

André Cristiano Silva Melo acsmelo@uepa.br

Universidade do Estado do Pará (UEPA), Bém, Pará, Brasil

Roselaine Ruviario Zanini rrzanini63@gmail.com

Universidade Federal de Santa Maria (UFSM), Santa Maria, Rio Grande do Sul, Brasil

\author{
RESUMO
}

O presente trabalho está situado em um produtor rural, fornecedor de hortaliças para uma rede de supermercados localizada na Região Metropolitana de Belém, por meio de consignação. A empresa assume total risco na venda dos produtos, pois precisa calcular a quantidade ideal de cada produto enviado, evitando desperdícios e mantendo um alto nível de serviço. Por esse motivo, o principal objetivo dessa pesquisa é utilizar métodos de previsão de demanda para dimensionar a oferta de hortaliças. Para isso, os dados coletados compreendem um período de 24 meses e foram agrupados por local de destino (supermercados). Foram aplicados aos dados os modelos de Suavização Exponencial Simples e Dupla, calculando assim seus coeficientes $(\alpha)$ e ( $($ ) . Os melhores modelos foram selecionados utilizando métricas de erros de previsão, sendo aplicados na realização de previsões para o mês posterior. Por fim, após o calculo da estimativa de consumo, foi possível dimensionar a quantidade ofertada de hortaliças, principal resultado deste estudo.

PALAVRAS-CHAVE: Previsão de demanda. Reposição de estoques. Hortaliças. Varejo. Dimensionamento da oferta. 


\section{INTRODUÇÃO}

O Ministério da Agricultura, Pecuária e Abastecimento descreve que a atividade agrícola no Brasil é extremamente favorável, pois dispõe de terras férteis, extensas e clima propício para a agricultura, destacando-se como um dos principais países produtores e fornecedores de alimentos (BRASIL, 2016). Todavia, devido à crescente demanda por alimentos e produtos agropecuários, a agricultura nacional enfrenta desafios para fornecer produtos para a sua população em quantidade e qualidade necessárias (BRASIL, 2016).

Dentre as atividades que compreendem a agricultura e pecuária, a produção de frutas e hortaliças representa um montante relevante da economia desse setor. Segundo dados do Instituto Brasileiro de Geografia e Estatística - IBGE (2006, apud HORTIBRASIL, 2009), o valor de produção de frutas e hortaliças, correspondentes a R\$ 26 bilhões, representam $26 \%$ do valor total da produção agrícola do país, abaixo apenas dos valores de produção de cereais, leguminosas e oleaginosas. Assim, tais dados evidenciam o destaque que a atividade de horticultura obtém em comparação a outras cadeias de base agrícola.

Nesse contexto, o estreitamento das relações entre lojas varejistas e produtores rurais tem mudado o cenário de comercialização de frutas, legumes e verduras, especialmente de hortaliças. Faulin e Azevedo (2003) e Souza (2001) afirmam que o setor varejista vem ocupando o lugar de feiras livres e se tornando o principal ponto de distribuição desses itens em diversas regiões do Brasil. Em virtude dessa corrida pela conquista do cliente, o varejo tem cada vez mais investido nesse tipo de parceria e, como consequência, muitos desses produtores têm sua produção dedicada a uma rede de varejo específica. No entanto, para atender a essa demanda, o produtor rural precisa gerar um volume considerável de produtos, e, consequentemente, os recursos envolvidos neste processo representam um montante proporcional. Por esse motivo, empregar tais recursos de forma eficiente, buscando atender a demanda a um menor custo, se faz indispensável.

Autores como Vilela et al. (2003) descrevem o setor agrícola como o campeão em perdas de alimentos, pois apresenta elevada depreciação da qualidade dos produtos, como consequência de deterioração causada por amassamentos, cortes, podridões e outros fatores. Nesse sentido, segundo Tofanelli et al. (2009), alguns causadores das perdas no setor de hortaliças são o alto volume comercializado de uma grande variedade de hortaliças e a alta perecibilidade desses itens. Por outro lado, Gruen, Corsten e Bharadwaj (2002) e Tofanelli et al. (2009), afirmam que a problemática das perdas no setor está concentrada em encontrar o equilíbrio para ofertar a quantidade ideal de hortaliças no varejo, conciliando um alto nível de serviço ao cliente e, ao mesmo tempo, diminuindo as perdas.

Nesse contexto, o presente trabalho está focado em um produtor rural, responsável por fornecer hortaliças a uma rede de supermercados localizada na Região Metropolitana de Belém, estado do Pará. Ademais, seus produtos são vendidos em consignação, ou seja, esta empresa é responsável pela escolha da quantidade de produtos a serem enviados diariamente a cada supermercado, que, por sua vez, repassa parte do valor para o fornecedor apenas das mercadorias vendidas. Assim, o restante não comercializado é devolvido ao produtor como forma de conferência e registro de perdas. 
Desse modo, o fornecedor assume total risco nas vendas dos produtos, tendo que decidir a quantidade ideal de cada produto a ser entregue diariamente para equilibrar o alto nível de serviço e o mínimo desperdício dos produtos. Por esse motivo, figura como principal objetivo deste estudo a elaboração de previsão de demanda voltada para a produção de hortaliças, objetivando dimensionar a oferta desses insumos, bem como reduzir as perdas desse material, rupturas neste processo, assim como manter um bom nível de serviço, através de um controle de estoques mais eficiente.

\section{MÉTODOS DE PREVISÃO}

O Bowersox et al. (2014) definem o processo de previsão da demanda como uma habilidade crítica antecessora à realização da venda. Nesse sentido, segundo eles, a previsão de demanda constitui uma técnica decisiva para orientar o atendimento dos requisitos dos clientes, referente à quantidade ofertada, bem como o meio onde ela será distribuída. Para Tubino (2009), a previsão permite aos gestores antever o futuro, fator fundamental nos processos de planejamento dos sistemas de produção. Analogamente, Fernandes e Godinho Filho (2010) complementam tal afirmação, pois segundo eles, esta técnica é fundamental para guiar o planejamento estratégico da produção, finanças e vendas de uma organização. Todavia, tais autores ressaltam a total ausência de vínculo entre os métodos de previsão e a adivinhação, enfatizando ser tal metodologia a utilização de um conjunto de procedimentos voltados pra entender questões mercadológicas.

Nesse sentido, a realização de uma previsão de demanda adequada carece de informações referentes à própria demanda, ou seja, ao consumo dos produtos, considerando, entretanto, a ocorrência de erros nesse processo. Portanto, para minimizá-los é fundamental ter cautela no processo de coleta de dados e escolha do modelo de previsão (MARTINS; LAUGENI, 2015). Diversos autores, como Lustosa et al. (2008), Tubino (2009) e Fernandes e Godinho Filho (2010), descrevem metodologias para realização da previsão de demanda. Apesar de haver discretas divergências quanto ao passo a passo, se podem observar grandes semelhanças na discrição do método pelos autores. Dentre eles, Tubino (2009) denomina as etapas segundo a seguinte ordem: Objetivo do Modelo; Coleta e Análise dos Dados; Seleção da Técnica de Previsão; Obtenção das previsões e Monitoramento do Modelo.

Paralelamente, segundo Tubino (2009) é imprescindível para a equipe de Planejamento e Controle da Produção compreender como a previsão de demanda é realizada, pois esta é a principal informação de entrada aplicada na elaboração de suas atividades, afetando diretamente na realização esperada de suas funções de planejamento e controle do sistema produtivo (TUBINO, 2009). Nesse sentido, existem na literatura especializada diversas técnicas de previsão, subdivididas em métodos qualitativos, ou subjetivos, e métodos quantitativos. Conforme abordado por Lustosa et al. (2008), os modelos quantitativos pode sem divididos entre métodos de Projeção (Médias Móveis, Suavização Exponencial, Projeção e Tendência, Decomposição, e Modelos ARIMA), assim como de Correção (Regressão Simples, Regressão Múltipla e Métodos Econométricos). Por outro lado, dentro dos métodos qualitativos, segundo os autores, é possível 
subdividi-los entre: Método Delphi, Pesquisa de Mercado e Simulação de Cenários, conforme a Figura 1.

Figura 1 - Alguns métodos de previsão de demanda

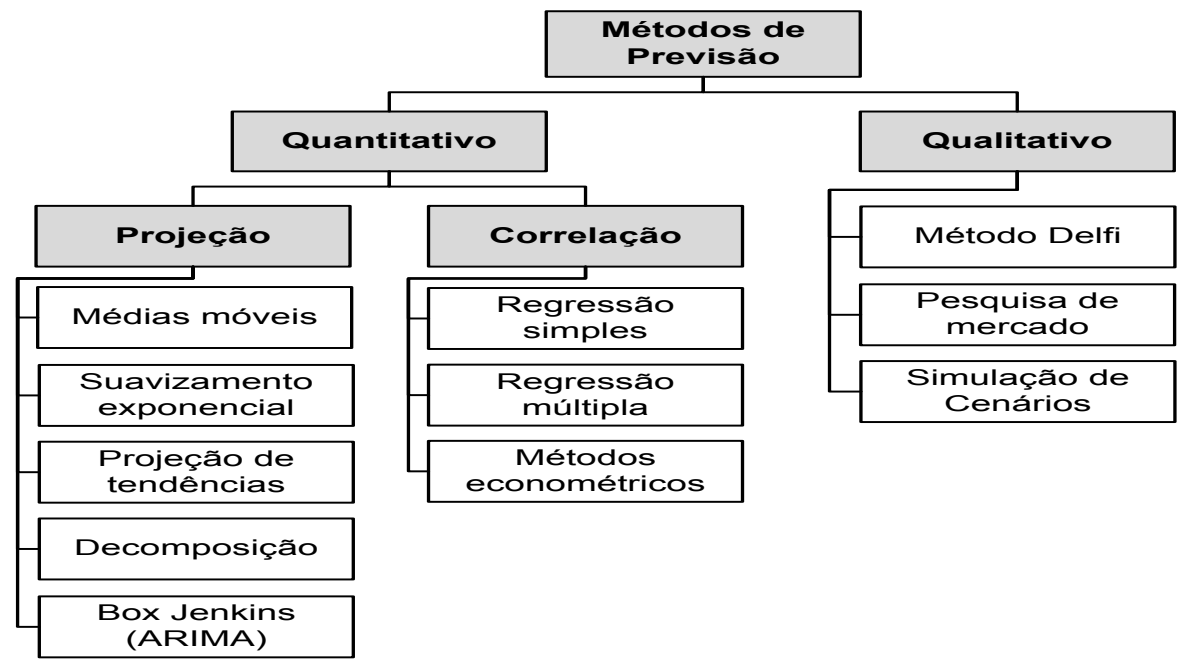

Fonte: Adaptado de Lustosa et al. (2008).

Dentro do âmbito quantitativo, as técnicas de séries temporais são métodos estatísticos que tomam como base dados históricos norteados por padrões e tendências relativamente claras e estáveis (BOWERSOX ET AL., 2014). Assim, abordagens fundamentadas em tais métodos implicam em previsões de demandas futuras baseadas em dados pretéritos, pois, de acordo com Fernandes e Godinho Filho (2010), se acredita na influencia das observações passadas nos acontecimentos futuros. Neste contexto, desse modo, o presente trabalho apresenta enfoque voltado para previsões de demanda de séries temporais, mais especificamente nos métodos de suavização exponencial simples e suavização exponencial dupla, expostos em sequência.

\section{MÉTODOS DE PREVISÃO POR SÉRIES TEMPORAIS}

O método de suavização exponencial, segundo Lustosa et al. (2008), estabelece pesos diferentes para cada parcela do cálculo da previsão, considerando uma média ponderada em que quanto mais recente o valor da série, maior o peso estabelecido a ela, decrescendo de forma exponencial. Ao mesmo tempo, segundo os mesmos autores, tal metodologia pode ser dividida de duas formas, simples e dupla, a saber:

\section{SUAVIZAÇÃO EXPONENCIAL SIMPLES}

É um método que considera os " $\mathrm{n}$ " períodos mais recentes para o cálculo, com a característica do método de suavização exponencial de estabelecer pesos decrescentes com o passar do tempo para cada observação. Segundo Fernandes e Godinho Filho (2008), o método é empregado para prever uma demanda com padrão constante e tem origem na minimização da somatória dos desvios $\left(d_{t}-a\right)$ ao quadrado. À vista disso, a técnica corrige o erro ocorrido no período atual (real 
- previsão) e fornece previsão para o próximo período por esse mesmo valor obtido. Procura-se minimizar o erro e se atribui um peso $(\alpha)$ a ele. Nas Equações 1,2 e 3 é descrito matematicamente o modelo.

$$
S_{T}=S_{T-1}+\alpha\left(d_{T} S_{T-1}\right)
$$

Considerando que:

$$
P_{T+k}=S_{t}
$$

Logo,

$$
S_{T-1}=P_{T}
$$

Sendo:

- $S_{T}$ : A previsão suavizada para o período T (atual);

- $S_{T-1}$ : A previsão suavizada para o período $\mathrm{T}-1$;

- $\alpha$ : A constante de suavização para base (limitado ao intervalo 0 e 1);

- $d_{T}$ : A demanda real no período $\mathrm{T}$;

- $P_{T+k}$ : A previsão para o período $\mathrm{T}+\mathrm{k}$.

Lustosa et al. (2008) esclarecem que a constante $\alpha$ é chamada de constante de suavização para base. Quanto mais próximo de zero for o valor desta constante, menor será a correção dos dados de base e mais suave será a curva de projeção. Por outro lado, quanto mais próximo de 1 for o valor da constante, maior será a correção e mais irregular será a série projetada. Entretanto, Tubino (2009) alerta que o presente método não é adequado para acompanhar demandas com grandes movimentos de tendência. Além disso, é fornecida apenas a previsão para o período imediatamente posterior, logo, para os períodos subsequentes se usaria o mesmo valor.

\section{SUAVIZAÇÃO EXPONENCIAL DUPLA}

O método de suavização exponencial dupla está classificado em métodos baseados em um processo com tendência. Tal técnica tenta solucionar a limitação referente à tendência do método citado anteriormente, considerando-a no processo, além de também estabelecer pesos para os dados mais recentes (FERNANDES; GODINHO FILHO, 2010). Segue, nas Equações 4, 5 e 6, a representação matemática do modelo.

$$
P_{T+k}=S_{T}+k T_{T}
$$

Considerando que:

$$
\begin{gathered}
S_{T}=\alpha d_{T}+(1-\alpha)\left(S_{T-1}+T_{T-1}\right) \\
T_{T}=\beta\left(S_{T}-S_{T-1}\right)+(1-\beta) T_{T-1}
\end{gathered}
$$

Sendo:

- $P_{T+k}:$ A previsão do período $\mathrm{T}+\mathrm{k}$;

- $S_{T}$ : A previsão suavizada exponencialmente para o período T;

- $k$ : O número de períodos futuros a serem previstos; 
- $T_{T}$ : A estimativa de tendência para o período $\mathrm{T}$;

- $d_{T}$ : a Demanda real no período T;

- $\alpha$ : A constante de suavização para a base (limitado ao intervalo de 0 a1);

- $\beta$ : A constante de suavização para tendência (limitado ao intervalo: 0 a 1).

Logo, a técnica de suavização exponencial dupla, assim como a técnica de suavização exponencial simples, fornecem previsões apenas para o próximo período imediato ao erro gerado pela última previsão, ou seja, ambos os métodos devem ser aplicados em programações de curto prazo (TUBINO, 2009).

\section{AVALIAÇÃO DOS MÉTODOS DE PREVISÃO}

Após selecionar a técnica de previsão mais adequada ao item e implantar o modelo, há necessidade de acompanhar o comportamento das previsões e ratificar sua validade, por meio de monitoramento, diante da dinâmica atual dos dados para manter a atualização do modelo e obter previsões de demanda confiáveis (TUBINO, 2009). Ademais, o processo de avaliar os métodos de previsão consiste em realizar acurácia das previsões, ou seja, verificar a diferença, ou desvio, entre a demanda real e a demanda prevista. Desse modo, para melhorar a acurácia do modelo aplicado, é necessário medir e analisar seus erros (BOWERSOX ET AL., 2014).

Para Lustosa et al. (2008), um desvio positivo significa que a demanda superou a previsão, enquanto que o negativo expressa que a demanda foi superada pela previsão, conforme ilustrado na Equação 7.

$$
E_{t}=D_{t}-F_{t}
$$

Sendo:

- $E_{t}:$ O erro de previsão para o período T;

- $D_{t}$ : O valor real da demanda;

- $F_{t}$ : O valor previsto da demanda (forecast)

Os erros das previsões podem advir de duas situações: a primeira é devido à própria aleatoriedade do mercado e não pode ser evitada, portanto, ignora-se esse fenômeno; a segunda é devido à escolha precipitada de parâmetros do método de previsão utilizado, acarretando em erros, que devem ser minimizados (FERNANDES; GODINHO FILHO, 2010). Ao mesmo tempo, segundo Martins e Laugeni (2015), para certificar que o parâmetro do modelo de previsão selecionado continue representando adequadamente o fenômeno verdadeiro, é preciso acompanhar o modelo escolhido por meio de instrumentos indicadores da real situação do fenômeno pelo modelo.

Nesse contexto, existem diversas medidas para avaliar e controlar os erros de previsão. Uma delas, segundo Fernandes e Godinho Filho (2010), é a somatória acumulada dos erros de previsão $\left(E_{T}\right)$. Ela aborda os erros da previsão conjuntamente, calculando o índice por meio da somatória dos erros de vários períodos (ver Equação 8). Assim, o bom comportamento da previsão não impede o acontecimento de variações aleatórias a cada período, podendo variar para mais ou para menos. Ressaltando, ao mesmo tempo, a necessidade dessas 
variações de ser aproximar de zero, pois ao longo do tempo as mesmas tendem a se anular.

$$
E_{T}=\sum_{t=1}^{T} E_{t}
$$

Os autores ainda comentam sobre o resultado desta equação, pois se ele apresentar valores distantes de zero, provavelmente há problemas no sistema de previsão, significando a presença de previsão tendenciosa. Paralelamente, se ET estiver crescendo ou decrescendo a uma taxa aproximadamente constante, indica a subestimação ou superestimação das previsões a uma taxa constante. Por outro lado, se o comportamento de ET se basear em uma taxa crescente, significa que o modelo de previsão utilizado está errado ou o processo se modificou e o modelo já não se enquadra.

Igualmente, o denominado de erro absoluto médio ou desvio absoluto médio (DAM), segundo Lustosa et al. (2008), demonstram a média dos desvios absolutos por meio do cálculo da somatória do módulo dos desvios, relacionados pelo número de períodos consecutivos (n), expressa segundo a na Equação 9:

$$
D A M=\frac{\sum_{t=1}^{n}\left|E_{t}\right|}{n}
$$

Fernandes e Godinho Filho (2010) afirmam que o DAM mede a dispersão dos erros, ou seja, a previsão estará próxima da demanda real se o valor de tal medida for pequeno. Ainda é citado que existem autores que defendem a relação entre a somatória acumulada dos erros de previsão e o desvio absoluto médio, em que o primeiro deve ser quatro vezes menor que o segundo para o modelo ser considerado bom.

O erro quadrático médio (EQM) é semelhante ao DAM, entretanto, estabelece pesos maiores para grandes desvios e menores para pequenos, pois se eleva cada desvio ao quadrado. Dessa forma, a medida não é expressa na mesma unidade dos dados de demanda, pois é desvantajoso para a análise. Entretanto, pode-se utilizar a raiz quadrada do EQM, apesar de não ser usual (LUSTOSA ET AL., 2008). Assim, segue, na Equação 10, a representação matemática da medida.

$$
E Q M=\frac{\sum_{t=1}^{n} E_{t}^{2}}{n}
$$

Por outro lado, a também denominada de porcentagem média absoluta, o EPAM vem a ser uma alternativa ao DAM, obtida por meio do cálculo da somatória dos desvios percentuais médios. Fernandes e Godinho Filho (2010) exemplificam esta medida, pois segundo eles o valor obtido indica em quantos por cento a previsão se afasta dos dados reais, sendo representado pela Equação 11, na sequência.

$$
\boldsymbol{E P A M}=\frac{\sum_{t=1}^{n}\left|\frac{E_{t}}{D_{t}}\right|}{n}
$$

O tracking signal (TS), ou sinal de rastreamento, indica o grau de viés da previsão, ou seja, indica se os desvios evidenciados são relacionados a alguma causa aleatória ou a um componente determinado (FERNANDES; GODINHO 
FILHO, 2010). Assim, se obtém tal medida por meio da relação entre a somatória acumulada dos erros e o desvio absoluto médio, conforme representa matematicamente a Equação 12.

$$
T S=\frac{E_{T}}{D A M}
$$

Paralelamente, os autores ainda citam a ocorrência de valores de TS normalmente distribuídos em torno de zero. Por esse motivo, eles sugerem que os limites de controle sejam compreendidos entre no máximo 4 DAM negativo e 4 DAM positivo. Logo, se o valor do sinal de rastreamento ultrapassar estes valores, é sinal da existência de motivos determinados que tenham causado o erro. Todavia, Martins e Laugeni (2015) comentam a desvantagem desse instrumento, pois, segundo eles, ela se relaciona com a necessidade de sempre calcular o tracking signal para cada período, a fim de impedir o crescimento excessivo da somatória acumulada dos erros da previsão, caso o modelo selecionado não seja o mais apropriado.

Ao mesmo tempo, de acordo com Martins e Laugeni (2015), o sinal de Trigg (TR) é um instrumento que procura retificar a distorção do método anteriormente citado. Trigg (1964, apud Nunes, 2014) afirma ser a estatística do sinal de Trigg possuidora da menor variância se comparado com o tracking signal. Desse modo, se pode obter o TR por meio da razão entre o erro médio exponencial (EME) e o desvio acumulado médio (DAM), conforme as Equações 13 e 14.

$$
T R=\frac{E M E}{D A M}
$$

Onde,

$$
E M E=\left(\text { DesvioMédio }_{t}\right)+(1-\alpha) E M E_{t-1}
$$

Com $0<\alpha<1$.

Ao mesmo tempo, visto que o EQM é uma medida que cresce exponencialmente. As Equações 15 e 16 expressam as funções objetivo para os métodos de Suavização Exponencial Simples e Dupla, bem como suas respectivas restrições, a saber:

$$
\operatorname{Min} \frac{\sum_{i=1}^{n} E Q M_{i}}{n}=\frac{\sum_{i=1}^{n} \sum_{t-1}^{m}\left\{D_{t}-\left[S_{T-1}+\alpha\left(d_{T}-S_{T-1}\right)\right]\right\}^{2} / m}{n}
$$

Sujeito à restrição: $0<\alpha<1$.

$$
=\frac{\sum_{i=1}^{n} \frac{\sum_{t-1}^{m}\left\{D_{t}-\alpha d_{T}+(1-\alpha)\left(S_{T-1}+\boldsymbol{T}_{T-1}\right)+k\left[\beta\left(S_{T}-S_{T-1}\right)+(1-\beta) T_{T-1}\right]\right\}^{2}}{m}}{n}
$$

Sujeito às restrições: $0<\alpha<1$

$$
0<\beta<1 .
$$




\section{OBJETO DE ESTUDO}

A empresa objeto deste estudo é uma produtora de hortaliças, localizada na zona rural da cidade de Castanhal, no Estado do Pará. Seus produtos são comercializados pelo método de consignação, em que o valor auferido com a comercialização depende apenas de parte da quantidade vendida, sendo o restante dos produtos devolvidos para a conferência. Ela produz dezenove tipos de hortaliças, sendo a distribuição feita por meio de um intermediário entre a entidade produtora e quatro supermercados, ambos situados na Região Metropolitana de Belém.

Ao mesmo tempo, ela é totalmente responsável pela quantidade diária de produtos ofertados à rede varejista, apresentando como única restrição, a obrigatoriedade em manter altos níveis de serviço para seus produtos. Fato este, extremamente pertinente, dada a extrema perecibilidade dos insumos ofertados.

Vale ressaltar a forma empírica como a instituição dimensiona sua produção, pois para o cálculo da quantidade ofertada de insumos, é considerada apenas a experiência do gestor responsável, bem como o histórico de vendas. Dessa forma, os produtos são distribuídos diariamente a todos os supermercados, no qual são contabilizados os itens ofertados, assim como os devolvidos, por estarem inadequados para a venda.

Após isto, calcula-se a diferença entre a entrada e a saída de produtos, realizando, desse modo, a estimativa das vendas para o dia em questão e o consequente dimensionamento da oferta. Por outro lado, dado a contabilidade quinzenal realizada pela rede varejista receptora, pode-se calcular o estoque médio de cada hortaliça pela diferença entre o total de produtos enviados (entrada - saída) na quinzena menos a quantidade vendida na quinzena.

\section{PROCEDIMENTOS DE COLETA DE DADOS}

Foram disponibilizados pela empresa dados históricos de fornecimento de hortaliças aos supermercados, assim como os de devolução de mercadorias não vendidas. Para as três lojas mais antigas, os dados abrangeram o período de 24 meses, entre setembro de 2014 a agosto de 2016. Para o supermercado inaugurado recentemente, o período foi de 10 meses entre dezembro de 2015 a setembro de 2016.

\section{PROCEDIMENTOS DE ANÁLISE DE DADOS}

A primeira etapa deste trabalho foi a organização dos dados. Como eles não apresentavam o valor real de vendas diárias, apenas os valores de fornecimento e devolução, foi preciso calcular a estimativa de vendas por meio da relação entre as duas variáveis. Nesse processo se constatou a disposição inadequada dos dados, sendo necessário reagrupar os valores coletados por supermercado (lojas A, B, C e D). 
Verificou-se também a ocorrência de valores nulos neste banco de dados, pois se referem a ocorrência de feriados, domingos facultativos ou simplesmente a rupturas devido à falta de produtos. Como tal abordagem proporcionaria um número limitado de informações, optou-se por completar tais lacunas com demandas ocorridas ao longo da semana, pois, segundo observado, elas ocorrem quando não há produto suficiente as quartas e os sábados.

O segundo passo compreendeu a seleção do melhor modelo de previsão a ser aplicado aos dados. Para isso, os métodos de Suavização Exponencial Simples e Dupla foram aplicados a todos os dados de venda de hortaliças, divididos por tipo de supermercado (Loja) de destino. Posteriormente, técnicas de seleção de modelos pelo menor erro foram aplicadas aos resultados, indicando os melhores modelos de previsão para cada caso, assim como seus respectivos coeficientes.

A terceira etapa desta pesquisa realizou previsão de demanda para o mês posterior. Utilizando os modelos selecionados foram realizadas previsões para um período adiante, objetivando dimensionar a quantidade a ser ofertada pela empresa. Os valores de demanda agregada prevista foram agrupados por lojas, sendo subdivididos por semana. Por fim, os resultados foram analisados e possibilitaram realizar discussões e conclusões a respeito da aplicação dos métodos preditivos, assim como de sua eficiência.

\section{RESULTADOS E DISCUSSÕES}

Nesta Seção serão apresentados os resultados do estudo, bem como suas discussões decorrentes.

\section{APLICAÇÃO DE MODELOS DE PREVISÃO NA DEMANDA POR HORTALIÇAS}

\section{Seleção do melhor método de previsão}

Conforme a nova organização dos dados coletados, as previsões de demanda foram realizadas por dia do mês para hortaliças vendidas por maço, assim como por dia da semana para as vendidas por quilograma, baseando-se no respectivo período anterior para efetivação dos cálculos.

$\mathrm{Na}$ execução da previsão de demanda pelo método da suavização exponencial simples, aplicadas pela utilização das Equações 1,2 e 3, foi considerada a constante de suavização $(\alpha)$ igual para todas as previsões do mesmo grupo de hortaliças de cada loja varejista. Da mesma forma, na previsão pelo método de suavização exponencial dupla, foram aplicadas as Equações 4, 5 e 6, considerando as constantes de suavização para base e para tendência, respectivamente $(\alpha)$ e $(\beta)$, com o mesmo valor para cada grupo de hortaliça de cada supermercado. Ao mesmo tempo, se considerou o valor de $(\mathrm{k})$ igual a 1 para todas as previsões, uma vez que se esperou conseguir apenas o resultado de um período futuro para todos os itens.

Paralelamente, a avaliação dos métodos das previsões foi feita pela aplicação das medidas ET, DAM, EQM, EPAM e TS, utilizando as Equações 8, 9, 10, 11 e 12, respectivamente. Nesse sentido, a fim de se obter o melhor desempenho possível para as previsões, o suplemento Solver do software Microsoft Excel para 
executar esta otimização. Ao mesmo tempo, dentre todas as medidas para avaliar os erros das previsões, se optou por utilizar como parâmetro para o cálculo de melhoria apenas o EQM, pois este estimador sofre maior variação por ser uma medida exponencial. Assim sendo, a função objetivo da programação é a minimização da média dos EQM dos dias do período, sejam dias da semana ou do mês, alterando as células variáveis de $(\alpha)$ para suavização exponencial simples ou $(\alpha)$ e $(\beta)$ para suavização exponencial dupla, considerando a restrição de valores obtidos dentro do intervalo compreendido entre zero e um $(0-1)$.

Nesse sentido, o método de otimização aplicado no Solver foi o do Gradiente Reduzido Generalizado (GRG), pois soluciona problemas de otimização não lineares, pois o EQM é uma medida que cresce exponencialmente. Nesse sentido, as Equações 15 e 16 foram utilizadas para este fim, já que expressam as funções objetivo de cada método de previsão e suas respectivas restrições para o presente estudo.

Todavia, apesar de as funções objetivos das otimizações visarem à minimização do EQM médio de cada previsão, o que importa verdadeiramente é o resultado da previsão de demanda das hortaliças para cada período que será gerado. Desse modo, os valores das previsões de hortaliças vendidas por maço devem ser inteiros. Entretanto, eles não foram adicionados como restrições dos sistemas, pois os valores das constantes $(\alpha)$ ou $(\alpha)$ e $(\beta)$ encontrados serão utilizados nas próximas previsões, que não necessariamente resultarão em valores inteiros para as próximas demandas (Tabelas 1, 2, 3 e 4).

\begin{tabular}{|c|c|c|c|c|c|c|c|}
\hline Loja & Grupo & Produto & Método & $\alpha$ & B & a geral & $\beta$ geral \\
\hline \multirow{19}{*}{ Loja A } & \multirow{3}{*}{1} & Alface & \multirow{3}{*}{ Dupla } & 0,90063 & 0,29253 & & \\
\hline & & Couve & & 0,89083 & 0,30496 & \multirow[t]{2}{*}{0,89265} & \multirow[t]{2}{*}{0,29725} \\
\hline & & Mastruz & & 0,8865 & 0,29426 & & \\
\hline & \multirow[t]{3}{*}{2} & Alfavaca & \multirow[t]{3}{*}{ Dupla } & 0,95544 & 0,24971 & \multirow[t]{3}{*}{0,95544} & \multirow[t]{3}{*}{0,24971} \\
\hline & & Cariru & & 0,88791 & 0,36175 & & \\
\hline & & Cheiro verde & & 0,88102 & 0,34493 & & \\
\hline & \multirow[t]{3}{*}{3} & Chicória & \multirow[t]{3}{*}{ Dupla } & 0,88688 & 0,34971 & \multirow[t]{3}{*}{0,88577} & \multirow[t]{3}{*}{0,35534} \\
\hline & & Manjericão & & 0,89628 & 0,34385 & & \\
\hline & & Mostarda & & 0,87674 & 0,37645 & & \\
\hline & \multirow{3}{*}{4} & Casadinho & \multirow{3}{*}{ Dupla } & 0,92065 & 0,21488 & \multirow{3}{*}{0,92487} & \multirow{3}{*}{0,21247} \\
\hline & & Espinafre & & 0,92909 & 0,21006 & & \\
\hline & & Cebolinha & & 0,89342 & 0,32461 & & \\
\hline & \multirow[t]{2}{*}{5} & Jambu & \multirow[t]{2}{*}{ Dupla } & 0,88341 & 0,3368 & \multirow[t]{2}{*}{0,8897} & \multirow[t]{2}{*}{0,32733} \\
\hline & & Salsa & & 0,89227 & 0,32059 & & \\
\hline & \multirow{2}{*}{6} & Feijão verde & \multirow{2}{*}{ Dupla } & 0,91279 & 0,26368 & \multirow{2}{*}{0,91226} & \multirow{2}{*}{0,25686} \\
\hline & & Rúcula & & 0,91173 & 0,25005 & & \\
\hline & 7 & Hortelã & Dupla & 0,92923 & 0,49142 & 0,92923 & 0,49142 \\
\hline & \multirow{2}{*}{8} & Jiló & \multirow{2}{*}{ Simples } & 0,158 & - & \multirow{2}{*}{0,15535} & \multirow[t]{2}{*}{ - } \\
\hline & & Quiabo & & 0,1527 & - & & \\
\hline
\end{tabular}

Fonte: Autoria própria (2016). 
No decorrer da pesquisa, foi convencionado o arredondamento para cima dos resultados a fim de melhor aderir ao atendimento da demanda. Desse modo, após a execução da otimização, pôde-se obter os melhores resultados dos cálculos das previsões após a seleção do melhor método de previsão para cada produto. Nesse contexto, para cada produto, a seleção do melhor método aplicado a cada loja foi feita pela observação do menor EQM médio. Sendo assim, o método de menor variação desse parâmetro para todos os estabelecimentos foi considerado como o ideal.

Em sequência, pôde-se observar que as hortaliças dos mesmos subgrupos (maço ou quilograma) obtiveram o mesmo método de previsão ideal em todos os supermercados. Ao mesmo tempo, não obstante a presença de valores diferentes para as mesmas hortaliças distribuídas para supermercados distintos, algumas leguminosas dispostas no mesmo ponto de venda apresentaram a mesma tendência de comportamento, ou seja, valores bem próximos. Por isso, foi possível agrupá-las segundo o supermercado respectivo de entrega.

Tabela 2 - Grupos de hortaliças e suas respectivas constantes gerais (Loja B)

\begin{tabular}{|c|c|c|c|c|c|c|c|}
\hline Loja & Grupo & Produto & Método & $\alpha$ & ß & $\alpha$ geral & $\beta$ geral \\
\hline \multirow{19}{*}{ Loja B } & \multirow{6}{*}{1} & Alface & \multirow{7}{*}{ Dupla } & 0,89014 & 0,32089 & \multirow{7}{*}{0,89613} & \multirow{6}{*}{0,33192} \\
\hline & & Alfavaca & & 0,8985 & 0,34601 & & \\
\hline & & Feijão verde & & 0,90012 & 0,32181 & & \\
\hline & & Jambu & & 0,89703 & 0,31175 & & \\
\hline & & Manjericão & & 0,891 & 0,34106 & & \\
\hline & & Salsa & & 0,9 & 0,35 & & \\
\hline & \multirow{4}{*}{2} & Cariru & & 0,88579 & 0,38181 & & \\
\hline & & Cebolinha & \multirow{3}{*}{ Dupla } & 0,87853 & 0,3851 & \multirow{3}{*}{0,87985} & \multirow{3}{*}{0,38586} \\
\hline & & Couve & & 0,8794 & 0,39418 & & \\
\hline & & Mostarda & & 0,87569 & 0,38235 & & \\
\hline & \multirow[t]{2}{*}{3} & Casadinho & Dupla & 0,87916 & 0,5101 & \multirow[t]{2}{*}{0,87916} & \multirow[t]{2}{*}{0,5101} \\
\hline & & Cheiro verde & & 0,88151 & 0,41252 & & \\
\hline & \multirow[t]{2}{*}{4} & Hortelã & Dupla & 0,88036 & 0,43582 & \multirow[t]{2}{*}{0,87982} & \multirow[t]{2}{*}{0,4276} \\
\hline & & Rúcula & & 0,8776 & 0,43446 & & \\
\hline & 5 & Chicória & Dupla & 0,90711 & 0,25456 & 0,90711 & 0,25456 \\
\hline & 6 & Espinafre & Dupla & 0,92378 & 0,19423 & 0,92378 & 0,19423 \\
\hline & 7 & Jiló & Simples & 0,11876 & - & 0,11876 & - \\
\hline & 8 & Mastruz & Dupla & 0,82727 & 0,57762 & 0,82727 & 0,57762 \\
\hline & 9 & Quiabo & Simples & 0,23555 & - & 0,23555 & - \\
\hline
\end{tabular}

Fonte: Autoria própria (2016).

Desse modo, foi criado um total de 34 grupos de hortaliças para todas as lojas, sendo alguns desses grupos compostos por apenas um produto. Assim, foram gerados 62 valores de constantes gerais diferentes para todos os grupos, que foram posteriormente utilizados para realizar os cálculos das previsões.

Tabela 3 - Grupos de hortaliças e suas respectivas constantes gerais (Loja C) 


\begin{tabular}{|c|c|c|c|c|c|c|c|}
\hline Loja & Grupo & Produto & Método & $\alpha$ & B & a geral & $\beta$ geral \\
\hline \multirow{19}{*}{ Loja C } & 1 & Alface & Dupla & 0,94408 & 0,23086 & 0,94408 & 0,23086 \\
\hline & \multirow{4}{*}{2} & Alfavaca & \multirow{4}{*}{ Dupla } & 0,90427 & 0,32488 & \multirow[t]{4}{*}{0,89581} & \multirow[t]{4}{*}{0,3237} \\
\hline & & Cariru & & 0,8995 & 0,32752 & & \\
\hline & & Cebolinha & & 0,88996 & 0,32882 & & \\
\hline & & Chicória & & 0,8895 & 0,3136 & & \\
\hline & \multirow[t]{3}{*}{3} & Casadinho & \multirow[t]{3}{*}{ Dupla } & 0,9519 & 0,11213 & 0,9519 & 0,11213 \\
\hline & & Cheiro verde & & 0,89952 & 0,27903 & \multirow[t]{6}{*}{0,90503} & \multirow[t]{6}{*}{0,28577} \\
\hline & & Feijão verde & & 0,90679 & 0,29759 & & \\
\hline & \multirow{4}{*}{4} & Hortelã & \multirow{4}{*}{ Dupla } & 0,90612 & 0,29236 & & \\
\hline & & Manjericão & & 0,90163 & 0,28519 & & \\
\hline & & Mostarda & & 0,91028 & 0,28529 & & \\
\hline & & Salsa & & 0,90585 & 0,27514 & & \\
\hline & 5 & Couve & Dupla & 0,87809 & 0,2738 & 0,87809 & 0,2738 \\
\hline & \multirow{2}{*}{6} & Jambu & \multirow{2}{*}{ Dupla } & 0,87544 & 0,3735 & \multirow[t]{2}{*}{0,87952} & \multirow[t]{2}{*}{0,35809} \\
\hline & & Rúcula & & 0,88359 & 0,34268 & & \\
\hline & \multirow{2}{*}{7} & Jiló & \multirow{2}{*}{ Simples } & 0,12029 & - & \multirow[t]{2}{*}{0,11571} & \multirow[t]{2}{*}{-} \\
\hline & & Quiabo & & 0,11113 & - & & \\
\hline & \multirow{2}{*}{8} & Mastruz & \multirow{2}{*}{ Dupla } & 0,89838 & 0,25008 & \multirow[t]{2}{*}{0,90246} & \multirow[t]{2}{*}{0,24946} \\
\hline & & Espinafre & & 0,90654 & 0,24883 & & \\
\hline
\end{tabular}

Fonte: Autoria própria (2016).

Tabela 4 - Grupos de hortaliças e suas respectivas constantes gerais (Loja D)

\begin{tabular}{|c|c|c|c|c|c|c|c|}
\hline Loja & Grupo & Produto & Método & $\alpha$ & ß & a geral & $\beta$ geral \\
\hline \multirow{19}{*}{ Loja D } & \multirow{2}{*}{1} & Alface & \multirow{2}{*}{ Dupla } & 0,87285 & 0,46068 & \multirow[t]{2}{*}{0,86796} & \multirow[t]{2}{*}{0,47025} \\
\hline & & Rúcula & & 0,86308 & 0,47981 & & \\
\hline & \multirow{2}{*}{2} & Alfavaca & \multirow{2}{*}{ Dupla } & 0,84105 & 0,5285 & \multirow[t]{2}{*}{0,83556} & \multirow[t]{2}{*}{0,53265} \\
\hline & & Chicória & & 0,83007 & 0,53679 & & \\
\hline & \multirow{3}{*}{3} & Cariru & \multirow{2}{*}{ Dupla } & 0,84458 & 0,45283 & \multirow[t]{2}{*}{0,8447} & \multirow[t]{2}{*}{0,43074} \\
\hline & & Espinafre & & 0,84483 & 0,40864 & & \\
\hline & & Casadinho & \multirow{3}{*}{ Dupla } & 0,90609 & 0,38206 & \multirow[t]{3}{*}{0,90004} & \multirow[t]{3}{*}{0,3779} \\
\hline & \multirow[t]{2}{*}{4} & Mostarda & & 0,91607 & 0,37467 & & \\
\hline & & Cebolinha & & 0,87796 & 0,37698 & & \\
\hline & \multirow{6}{*}{5} & Cheiro Verde & \multirow{6}{*}{ Dupla } & 0,86755 & 0,43685 & \multirow[t]{6}{*}{0,87373} & \multirow[t]{6}{*}{0,42396} \\
\hline & & Jambu & & 0,88292 & 0,42291 & & \\
\hline & & Salsa & & 0,86502 & 0,41081 & & \\
\hline & & Feijão verde & & 0,86347 & 0,42328 & & \\
\hline & & Mastruz & & 0,8852 & 0,41821 & & \\
\hline & & Hortelã & & 0,87825 & 0,43168 & & \\
\hline & 6 & Couve & Dupla & 0,88505 & 0,33683 & 0,88505 & 0,33683 \\
\hline & 7 & Jiló & Simples & 0,06535 & - & 0,06535 & - \\
\hline & 8 & Manjericão & Dupla & 0,91866 & 0,27872 & 0,91866 & 0,27872 \\
\hline & 9 & Quiabo & Simples & 0,23457 & - & 0,23457 & - \\
\hline
\end{tabular}

Fonte: Autoria própria (2016). 
Com a seleção dos métodos de previsão ideais para cada hortaliça, foram organizados os valores das demandas gerados por eles, explicitando o nome dos produtos, a demanda agregada prevista para a semana, bem como o valor previsto. Assim as previsões foram elaboradas para um mês a diante, já com arredondamento, para os produtos vendidos por maço nas lojas $A, B, C$ e $D$, segundo as Tabelas 5 e 6, na sequência.

Tabela 5 - Demanda prevista por maço para as lojas A e B

\begin{tabular}{|c|c|c|c|c|c|c|c|c|}
\hline \multirow[b]{2}{*}{ Produto } & \multicolumn{4}{|c|}{ Loja A } & \multicolumn{4}{|c|}{ Loja B } \\
\hline & $1^{\circ} \mathrm{Sem}$ & $2^{\circ} \mathrm{Sem}$ & $3^{\circ}$ Sem & $4^{\circ} \mathrm{Sem}$ & $1^{\circ} \mathrm{Sem}$ & $2^{\circ} \mathrm{Sem}$ & $3^{\circ} \mathrm{Sem}$ & $4^{\circ} \mathrm{Sem}$ \\
\hline Alface R. & 1822 & 1309 & 1345 & 2170 & 1663 & 1319 & 779 & 1747 \\
\hline Alfavaca & 163 & 237 & 172 & 164 & 147 & 140 & 151 & 166 \\
\hline Cariru & 435 & 403 & 274 & 508 & 408 & 365 & 322 & 458 \\
\hline Casad. & 805 & 678 & 623 & 995 & 804 & 773 & 641 & 1002 \\
\hline Cebol. & 2238 & 1538 & 1490 & 2185 & 1384 & 1289 & 1205 & 1884 \\
\hline C. V. & 7964 & 6330 & 6995 & 10190 & 7819 & 5929 & 6505 & 9482 \\
\hline Chic. & 1522 & 1209 & 1237 & 1573 & 1399 & 1023 & 979 & 1367 \\
\hline Cou-ve & 5117 & 4546 & 4013 & 4936 & 4218 & 3623 & 3850 & 3998 \\
\hline Esp. & 625 & 566 & 459 & 878 & 468 & 497 & 428 & 694 \\
\hline F. V. & 1882 & 1604 & 733 & 1951 & 1820 & 1308 & 1234 & 1888 \\
\hline Hort. & 669 & 584 & 543 & 735 & 573 & 499 & 494 & 661 \\
\hline Jam-bu & 1241 & 1262 & 777 & 1501 & 911 & 945 & 625 & 881 \\
\hline Manj. & 217 & 215 & 210 & 281 & 186 & 175 & 198 & 456 \\
\hline Mas-truz & 94 & 100 & 98 & 138 & 119 & 119 & 124 & 164 \\
\hline Most. & 56 & 79 & 47 & 79 & 75 & 73 & 68 & 75 \\
\hline Rúcu-la & 144 & 161 & 148 & 255 & 140 & 140 & 136 & 208 \\
\hline Salsa & 3086 & 2201 & 2270 & 3138 & 1792 & 1577 & 1535 & 2126 \\
\hline
\end{tabular}

Fonte: Autoria própria (2016).

Tabela 6 - Demanda prevista por maço para as lojas C e D

\begin{tabular}{ccccccccc} 
& \multicolumn{9}{c}{ Loja C } & & & \multicolumn{5}{c}{ Loja D } \\
Produto & $1^{\circ}$ Sem & $2^{\circ}$ Sem & $3^{\circ}$ Sem & $4^{\circ}$ Sem & $1^{\circ}$ Sem & $2^{\circ}$ Sem & $3^{\circ}$ Sem & $4^{\circ}$ Sem \\
\hline Alface R. & 1544 & 1203 & 906 & 1447 & 2008 & 1573 & 1060 & 1976 \\
Alfavaca & 99 & 109 & 130 & 143 & 144 & 127 & 138 & 134 \\
Cariru & 382 & 276 & 246 & 374 & 386 & 376 & 223 & 511 \\
Casad. & 843 & 779 & 641 & 952 & 673 & 680 & 702 & 1000 \\
Cebol. & 1907 & 1427 & 1164 & 1779 & 1492 & 1434 & 1270 & 1702 \\
C. V. & 6810 & 5571 & 5072 & 8403 & 6131 & 5952 & 5634 & 8038 \\
Chic. & 1416 & 994 & 920 & 1187 & 1197 & 1036 & 956 & 1734 \\
Cou-ve & 2559 & 3777 & 2953 & 2469 & 2685 & 3787 & 2598 & 4433 \\
Esp. & 435 & 361 & 338 & 561 & 436 & 416 & 309 & 562 \\
F. V. & 1756 & 1277 & 1213 & 1863 & 1839 & 1223 & 1019 & 1101 \\
Hort. & 374 & 406 & 319 & 741 & 417 & 404 & 363 & 585 \\
Jam-bu & 859 & 960 & 634 & 1046 & 1003 & 1160 & 836 & 1132 \\
Manj. & 186 & 138 & 102 & 175 & 91 & 105 & 106 & 225 \\
Mas-truz & 87 & 83 & 82 & 110 & 86 & 86 & 73 & 88
\end{tabular}




$\begin{array}{ccccccccc}\text { Most. } & 43 & 79 & 45 & 65 & 73 & 96 & 59 & 73 \\ \text { Rúcu-la } & 139 & 123 & 135 & 168 & 136 & 160 & 111 & 175 \\ \text { Salsa } & 1716 & 1527 & 1502 & 2634 & 2484 & 2654 & 2229 & 2489\end{array}$

Fonte: Autoria própria (2016).

Ao mesmo tempo, as previsões dos itens comercializados por quilograma são demonstradas por meio do total agregado presente na Tabela 7, na sequência:

Tabela 7 - Demandas agregadas previstas $(\mathrm{Kg})$ para as lojas A, B, C e D

\begin{tabular}{ccccccccc} 
Produto & \multicolumn{8}{c}{ Dia da Semana } \\
& Dom & Seg & Ter & Qua & Qui & Sex & Sáb \\
Jiló & 0 & 0 & 0 & 79,18 & 0 & 0 & 76,43 \\
Quiabo & 0 & 0 & 0 & 134,43 & 0 & 0 & 258,98 \\
\hline
\end{tabular}

Fonte: Autoria própria (2016).

Os valores das demandas dos itens comercializados por quilograma não foram arredondados, pois a unidade de venda permite que seja fornecido exatamente o que foi previsto. Porém, a previsão de demanda para todos os itens precisa ser realizada periodicamente, após retroalimentação do sistema com novos dados de demanda. Por meio desse processo é possível realizar o dimensionamento da oferta fundamentado nos dados de demanda previstos para o período subsequênte.

Apesar disso, a realização de previsão e a obtenção de um método para realizá-la constitui uma contribuição importante no segmento de produção de hortaliças. Conforme abordado por Faulin e Azevedo (2013) e Tofanelli (2009), este segmento apresenta importantes limitações. Em ambos os trabalhos, são apresentados os problemas de excesso de oferta de produtos, assim como o elevado desperdício dos mesmos, ocasionado pela alta perecibilidade e por falhas no dimensionamento da quantidade oferecida. Este trabalho está focado exatamente na solução desses problemas, sendo os resultados apresentados uma forma de minimizar essas falhas.

\section{CONSIDERAÇÕES FINAIS}

O presente trabalho propiciou o aumento da eficiência da previsão de demanda de hortaliças na empresa citada, pois retirou o viés empírico do cálculo da oferta. Para isso, a coleta e sistematização dos dados históricos de vendas foram necessárias, assim como a quantificação deste problema por meio de métodos de previsão. Ao mesmo tempo, esta pesquisa viabilizou a proposição de um método de previsão de demanda para as dezenove hortaliças produzidas pela microempresa estudada, assim como fornecidas para quatro lojas da mesma rede varejista, pois possibilitou a criação de um sistema para realizar previsões um período adiante.

Por outro lado, esta pesquisa apresentou limitações quanto aos dados coletados, visto que não foi possível obter a demanda real dos supermercados, utilizando, portanto uma estimativa calculada pela empresa próxima da realidade em questão. Ademais, também houve limitações quanto aos dados dos itens vendidos por quilograma, pois o abastecimento destes produtos não é feita diariamente. Por esse motivo, figura como sugestão para a empresa a coleta e o 
registro dos dados de vendas diárias nos caixas dos supermercados em um banco computadorizado, para utilizá-los como entrada para o cálculo das previsões de demanda e aumentar a confiabilidade dos seus resultados. Desta forma, esta organização agrícola e a rede varejista estarão fortalecendo sua relação na cadeia de suprimentos que as envolve por meio do compartilhamento de informações.

Todavia, apesar de todas as limitações encontradas neste trabalho, é possível considerar alcançado o objetivo geral proposto neste trabalho, pois foi possível construir uma metodologia para o cálculo da demanda. Consequentemente, foi possível auxiliar esta empresa na tomada de decisão a respeito de quando e quanto plantar de cada produto para: manter um nível de serviço adequado aos clientes, diminuir a incidência de rupturas, reduzir perdas nos supermercados e, principalmente, minimizar os custos com manutenção de estoques. Dessa forma, a microempresa, responsável tanto pela produção quanto pelo abastecimento dos itens, poderá gerenciar a reposição dos estoques nos supermercados de maneira mais eficiente, beneficiando desse modo todos os elos da cadeia de suprimentos, pois aumentará a satisfação dos clientes, assim como a sua credibilidade quanto fornecedora.

Por fim, dada as limitações dessa pesquisa, sugerem-se como trabalho futuro a elaboração de um Plano Mestre de Produção englobando todas as etapas de produção de hortaliças, ou seja, o plantio, a colheita e o ressuprimento desses insumos na rede varejista citada; assim como a realização de simulações de cenários e tendências para o ambiente externo, com a finalidade testar o comportamento da demanda frente a diversos futuros possíveis. Paralelamente, a fim de validar o método de previsão proposto, se sugere também a aplicação do mesmo em outras empresas distribuidoras de produtos perecíveis. 


\title{
Sizing the supply of perishable products to a retail network through forecasting methods
}

\begin{abstract}
The present work is located in a rural producer, supplier of vegetables to a supermarket chain located in the Metropolitan Region of Belém, through consignment. The company takes full risk in the sale of the products, as it needs to calculate the ideal quantity of each product sent, avoiding waste and maintaining a high level of service. For this reason, the main objective of this research is to use demand forecasting methods to estimate the supply of vegetables. For this, the data collected comprised a period of 24 months and were grouped by place of destination (supermarkets). The Simple and Double Exponential Smoothing models were applied to the data, thus calculating their coefficients $(\alpha)$ and $(\beta)$. The best models were selected using prediction error metrics, and were applied to predictions for the following month. Finally, after calculating the consumption estimate, it was possible to size the amount of vegetables offered, the main result of this study.
\end{abstract}

KEYWORDS: Forecast of demand. Stock replenishment. Vegetables. Retail. Sizing of supply. 


\section{REFERÊNCIAS}

BRASIL. Ministério da Agricultura, Pecuária e Abastecimento. Vegetal: Mercado Interno. Brasília, 2016. Disponível em:

<http://www.agricultura.gov.br/vegetal/mercado-interno> Acesso em: 16 de Mar. de 2017.

BOWERSOX, D. J. et al. Gestão Logística da Cadeia de Suprimentos. Tradução: Luiz Claudio de Queiroz Faria. 4. ed. Porto Alegre: Bookman, 2014. 455 p.

FAULIN, E. J.; AZEVEDO, P. F. Distribuição de hortaliças na agricultura familiar: uma análise das transações. Informações Econômicas, São Paulo, v. 33, n. 11, p.24-37, nov. 2013. Disponível em: <http://www.iea.sp.gov.br/out/publicacoes/pdf/tec3-1103.pdf>. Acesso em: 10 set. 2016.

FERNANDES, F. C. F.; GODINHO FILHO, M.. Planejamento e Controle da Produção: Dos Fundamentos ao Essencial. 1. ed. São Paulo: Atlas, 2010. 275 p.

GRUEN, T. W.; CORSTEN, S. D.; BHARADWAJ, S. Retail Out-of-Stocks: A Worldwide Examination of Extent, Causes and Consumer Responses. Washington: GMI/FMI, 2002.

HORTIBRASIL. Diagnóstico da Olericultura, 2009. [S.I.], 2009. Disponível em: <http://www.hortibrasil.org.br/index.php/novidades-no-mercado/79-geral/1135diagnostico-da-olericultura> Acesso em: 14 Mar. 2017.

LUSTOSA, L. J. et al. Planejamento e Controle da Produção. 1. ed. Rio De Janeiro: Elsevier, 2008. 357 p.

MARTINS, P. G.; LAUGENI, F. P. Administração da Produção. 3. ed. São Paulo: Saraiva, 2015. 562 p.

NUNES, D. R. L. Gestão de suprimentos no varejo: Sistemas de reposição de estoques em duas camadas e análise de esquemas de monitoramento da previsão de demanda. 2014. 95 f. Tese (Doutorado) - Curso de Engenharia de Produção, Departamento de Engenharia Industrial, Pontifícia Universidade Católica do Rio de Janeiro, Rio de Janeiro, 2014.

SILVA, E. L.; MENEZES, E. M. Metodologia da pesquisa e elaboração de dissertação. 4 ed. Revista Atual. UFSC, Florianópolis SC, 2005. 
SOUZA, K. C. G. N. Modelo de gestão de estoques para bens de consumo em supermercados. 2012. 93 f. Tese (Doutorado) - Curso de Engenharia de Sistemas Logísticos, Departamento de Engenharia de Produção, Escola Politécnica da Universidade de São Paulo, São Paulo, 2012.

TOFANELLI, M. B. D. et al. Levantamento de perdas em hortaliças frescas na rede varejista de Mineiros. Horticultura Brasileira, Brasília, v. 27, n. 1, jan. 2009. Disponível em: < http://www.scielo.br/pdf/hb/v27n1/24.pdf>. Acesso em: 17 out. 2016.

TUBINO, D. F. Planejamento e Controle da Produção: teoria e prática. 2. ed. São Paulo: Atlas, 2009. 208 p.

VILELA, N. J. et al. Perdas na comercialização de hortaliças em uma rede varejista do Distrito Federal. Cadernos de Ciência \& Tecnologia, Brasília, v. 20, n. 3, set. 2003. Disponível em:

<https://www.alice.cnptia.embrapa.br/bitstream/doc/109801/1/v20n305.pdf>. Acesso em: 20 jan. 2017.

SILVA, F. S. et al. Dimensionamento da oferta de produtos perecíveis a uma rede varejista por meio de métodos de previsão. R. Gest. Industr., Ponta Grossa, v. 14, n. 4, p. 240-258, out./dez. 2018. Disponível em: $<$ https://periodicos.utfpr.edu.br/rgi >. Acesso em: XXX.

Correspondência:

Antonio do Nascimento Branco

Rua Robson Flores, q.11 casa 15, Camobi, Santa Maria, RS, Brasil.

Direito autoral: Este artigo está licenciado sob os termos da Licença Creative Commons-Atribuição 4.0

Internacional.

\section{(c) (i)}

